\title{
USE OF SPECTRAL DECOMPOSITIO IN THE IDENTIFICATION OF KARSTIFIED AREAS IN BM-C-33 BLOCK AND THE APPLICATION IN THE 3D GEOLOGICAL MODELING - PRE-SALT, CAMPOS BASIN, BRAZIL
}

\author{
Carvalho, P.G. ${ }^{1 *}$; Costa, P.N. ${ }^{1}$; Bastos, E.M. ${ }^{2}$ Braga, D.D. ${ }^{1}$; Walter,P.H. ${ }^{1}$; Canova, M.D. ${ }^{1}$ \\ ${ }^{1}$ Petrobras - Petróleo Brasileiro S.A; ${ }^{2}$ Halliburton \\ Copyright 2021, SBGf - Sociedade Brasileira de Geofisica. \\ This paper was prepared for presentation during the $17^{\text {th }}$ International Congress of the Brazilian Geophysical Society held in Rio de Janeiro, Brazil, $16-19$ August 2021 . \\ Contents of this paper were reviewed by the Technical Committee of the $17^{\text {th }}$ International Congress of the Brazilian Geophysical Society and do not necessarily represent any position of \\ the SBGf, its officers or members. Electronic reproduction or storage of any part of this paper for commercial purposes without the written consent of the Brazilian Geophysical Society is
} prohibited.

\begin{abstract}
The exploratory BM-C-33 block is located in Campos Basin and the main reservoir are silicified carbonate rocks (Macabu Fm.), followed by volcanic rocks (Cabiúnas Fm.?). The intense diagenesis results in challenges and limitations in the process of matrix properties modeling. Therefore, the prediction and modeling of dissolution features, such as paleo caves, are complex. The secondary permo-porous system modeling requires a data compilation and an integrated analysis from different data sources such as: drilling history of circulation losses, borehole image interpretation, structural restoration and seismic attributes.

The wells drilling history shows that circulation losses zones are relatively common. These zones can provide information about non-matrix properties. As a first approach, the analysis well by well has shown that the main losses occur on the top of seismic mounds structures (upper stratigraphic zone) and on the upper part of clinoforms (lower stratigraphic zone). The crossplot maximum loss flow rate vs total volume, applied for conventional drilling, indicates which feature is most likely responsible for the increase of permo-porosity for each loss interval. This graph presents 5 classes: I - Mixed features (matrix domain); II - Connected vugs or natural fractures; III - Natural Fractures; IIIa - Enhanced Natural fractures and IV - Caves. After that, the graph data classification was checked by borehole images. As a result, samples from damage zones were classified as region III and intervals with relevant losses and complex historical drilling, overlapped region IV. Low losses intervals associated with discrete dissolution on borehole images overlapped classes I and II.

On seismic scale, the spectral decomposition technique was used to identify the karstified regions. This technique turns, through the Discrete Fourier Transform, the seismic data in time (TWT) to frequency domain. The application on this study case aims to identify dissolution features not evident on other seismic attributes by itself, such as amplitude and acoustic impedance. The analysis and interpretation for the studied area was carried out using RGB maps created by the combination of 3 different frequency contents. The features interpreted as karstified areas show rounded shapes with darkish coloring, associated with low amplitudes. These anomalies are compatible in depth with loss of circulation reported on the wells.

The spectral decomposition applied on the identification of karstified zones allowed us to improve the BM-C-33 3D geological model. On mounds structures, the seismic attributes were able to delimit the occurrence of paleo caves. In the lower stratigraphic zone, the spectral decomposition analysis was applied combined with paleo topography from structural restoration. The RGB map has shown circular features interpreted as paleo dolines, concentrated in paleo high. The correlative dissolution features between the wells were interpreted as indicative of the paleo groundwater levels. They were modeled according to the model proposed for Guam Island, Western Pacific. Thus, the use of spectral decomposition in the 3D model workflow has increased the reliability of the karst model and enhanced the DST matching.
\end{abstract}

